\title{
Ornamen Masjid Sunan Ampel, Sunan Giri, dan Sunan Sendang
}

\author{
Budiono $^{1}$, Nanik Rachmaniyah ${ }^{2}$, Aria Weny Anggraita ${ }^{3}$ \\ ${ }^{123}$ Departemen Desain Interior, FDKBD, Institut Teknologi Sepuluh Nopember, Surabaya \\ 1 budiono@interior.its.ac.id
}

\begin{abstract}
ABSTRAK
Bangunan yang dinilai mampu mewakili keberhasilan penerapan prinsip arsitektur Islam adalah Masjid. Karakteristik arsitektur masjid secara rinci dapat dilihat melalui morfologi, teknologi, dan artikulasi desainnya. Morfologi masjid meliputi organisasi spatial serta bentuk atap, aspek teknologi meliputi struktur, konstruksi, dan material bangunannya. Sedangkan karakteristik artikulasi desain lebih ditekankan pada bahasa dekoratif dan keteraturan desainnya. Analisis tentang morfologi, teknologi dan artikulasi desain dari arsitektur masjid yang terjadi saat ini perlu dilakukan guna memperoleh temuan terkait pengaruh dari budaya lokal atau non-lokal, serta terkait ciri-ciri yang bisa dikatagorikan sebagai arsitektur Islam/Islami.

Penelitian ini hanya membatasi pada kajian karakteristik artikulasi dari ornamen masjid. Masjid yang dipilih untuk diteliti ornamennya adalah masjid Wali di Jawa Timur yaitu masjid Sunan Ampel di Surabaya, masjid Sunan Giri di Gresik, dan masjid Sendang Duwur di Lamongan. Masjid Wali dipilih karena dianggap mewakili prototip masjid awal atau tradisional di Indonesia. Tujuan khusus dari penelitian ini adalah : Pertama, mendeskripsikan dan memetakan karakteristik visual dari salah satu elemen masjid yang menjadi salah satu warisan budaya yaitu ornamen masjid Wali. Kedua, menemukenali prinsip artikulasi desain pada masjid Wali sebagai salah satu wujud penerapan kaidah arsitektur/desain Islam pada era Wali di Indonesia.

Setelah ditetapkan state of the art penelitian, masalah penelitian serta kajian teori yang mendukung, maka penelitian ini dilakukan dengan kegiatan: pengumpulan data lapangan dengan observasi dan wawancara, pembuatan visualisasi berupa gambar dua dimensi dari ornamen yang terpilih, analisis bentuk dan interpretasi makna ornamen, serta kesimpulan. Luaran yang ditargetkan dari penelitian ini adalah berupa deskripsi bentuk dan makna ornamen masjid Wali, serta rumusan konsepsi karakteristik ornamen masjid yang berbasis budaya lokal dan Islam di Indonesia.
\end{abstract}

Kata kunci: Budaya lokal; Desain; Islam; Masjid; Ornamen

\section{ABSTRACT}

The building considered to represent the successful application of Islamic architectural principles is the mosque. The architectural characteristics of the mosque can see through its morphology, technology, and design articulation. The morphology of the mosque includes spatial organization and roof form. Technological aspects include structure, construction, and building materials. The characteristics of design articulation emphasized the decorative language and the order of the design. Analysis of the current morphology, technology, and design articulation of mosque architecture needs to be carried out in order to obtain findings regarding the influence of local or non-local cultures, as well as related characteristics that can be categorized as Islamic architecture/design.

The research is limited to only the study of the design articulation characteristics of the mosque ornament elements. The mosques chosen to researched were the Wali mosque in East Java, namely the Sunan Ampel mosque in Surabaya, the Sunan Giri mosque in Gresik, and the Sendang Duwur mosque in Lamongan. The Wali Mosque chose because it considers representing the prototype of an early or traditional mosque in Indonesia. The specific objectives of this study are: First, to describe and map the visual characteristics of the Wali mosque ornament which is one of the local cultural heritages. Second, to identify the principles of design articulation in the Wali mosque ornament as a manifestation of Islamic architectural/design principles in the Wali era in Indonesia. 
After determining the state of the art, research problems, and supporting theoretical studies, this research was carried out with the following activities: field data collection by observation and interviews, visualization in the form of 2-dimensional images of selected ornaments, form analysis, and interpretation of ornament meanings, and conclusions. The output of this research is a description of the form and meaning of the Wali mosque ornament. Apart from that, the formulation of the character concept of mosque ornament base on local culture and Islam in Indonesia.

Keywords: Local culture; Islam; Design; Mosque; Ornament

\section{PENDAHULUAN}

Masjid Wali merupakan prototip masjid awal di pulau Jawa sekaligus di Indonesia. Pendapat yang paling kuat tentang asal mula bentuk masjid di Jawa adalah yang menyatakan bahwa bentuk masjid di Jawa berasal dari bentuk bangunan umum masyarakat setempat (local community building) tanpa menyebut secara spesifik fungsi bangunan tersebut (Budi, 2004). Arsitektur masjid Wali sebagai wujud utama arsitektur Islam di Jawa juga merupakan wujud ekspresi lokal serta bukan merupakan prototip arsitektur Hindu-Budha yang ada sebelumnya (Wahby, 2007). Arsitektur masjid awal di Jawa yang dikenal sebagai arsitektur Masjid Wali adalah arsitektur yang lahir dari budaya lokal sehingga menjadi identitas budaya lokal. Ornamen merupakan elemen yang ikut memberi karakter khusus pada arsitektur masjid Wali sehingga menjadi identitas budaya.

Penelitian sebelumnya yang terkait dengan topik ornamen masjid sebagai warisan arsitektur Islam di Indonesia antara lain adalah: penelitian tentang ornamen gapura dan masjid Ampel sebagai kekhasan lokal (Adiani, 2015), penelitian tentang bentuk dan makna simbolik ragam hias masjid Sunan Giri (Pradana, 2019), penelitian tentang estetika dan makna simbolik ornamen makam Sendang Duwur (Iswati, 2016), penelitian tentang aspek akulturasi pada kepurbakalaan Sendang Duwur (Wiandik dkk, 2014), penelitian tentang estetika ragam hias candi bentar dan paduraksa di Jawa Timur (Wardani dkk, 2015), penelitian tentang bentuk ragam hias bangunan awal Islam di Jawa (Munandar, 1999), penelitian tentang sejarah kebudayaan dan semiotika ragam hias beberapa masjid di Jawa (Sunaryo dkk, 2016), penelitian tentang nilai multikultural ornamen masjid Wali di pesisir utara Jawa (Supatmo $\mathrm{dkk}, 2019)$. Dari hasil penelitian diatas diperoleh state of the art yang mendasari penelitian ini yaitu bahwa ornamen sebagai salah satu elemen masjid Wali memiliki keragaman bentuk yang khas, merupakan hasil akulturasi budaya lokal (Hindu/Budha) dan non-lokal (Islam), serta mempunyai nilai simbolis selain nilai estetis. Dari state of the art tersebut ditemukan celah penelitian yaitu masih diperlukannya penelitian lanjutan guna menghasilkan deskripsi visual beserta makna simboliknya dari ornamen secara menyeluruh dari tiga masjid Wali di Jawa Timur tersebut diatas.

Penelitian ini bertujuan untuk mendukung upaya pelestarian dan pengembangan desain ornamen tradisional pada masjid Wali sebagai salah satu warisan arsitektur Islam dan budaya Indonesia dengan pembuatan gambar detail ornamen masjid Wali di Jawa Timur serta perumusan konsepsi desain ornamen masjid yang berbasis budaya lokal dan Islam.

\section{METODE PENELITIAN}

Strategi penelitian yang dipilih untuk penelitian ini adalah Deskriptif Kualitatif dan Interpretatif, serta Komparatif. Penelitian deskriptif untuk memperoleh data kualitatif dengan cara mengobservasi artefak ornamen masjid serta konteks hubungan masjid dengan lingkungan sosial dan budayanya. Penelitian Komparatif dimaksudkan untuk mengidentifikasi kesamaan dan perbedaan bentuk dan makna antar ornamen masjid yang distudi serta antara ornamen masjid yang distudi dengan ornamen pra-Islam (Hindu dan Budha). 


\section{A. Metode Pengumpulan Data}

Pengumpulan data dilakukan melalui observasi, wawancara dan penelusuran dokumen. Observasi dikakukan untuk mengamati dan merekam karakteristik fisik ornamen masjid, posisi ornamen, serta gejala dan fenomena terkait keberadaan ornamen. Perekaman dilakukan melalui observasi langsung serta wawancara. Observasi langsung dilakukan dengan teknik sketsa, penggambaran dan foto. Wawancara dilakukan terhadap pihak pengguna, takmir masjid dan pihak yang memahami dan memiliki pengetahuan mendalam terkait sasaran penelitian. Kasus studi yang dipilih adalah yang paling relevan, yaitu ornamen pada: masjid Sunan Ampel di Surabaya, masjid Sunan Giri (masjid Ainul Yaqin) di Gresik, dan masjid Sunan Sendang di Paciran, Lamongan.

\section{B. Metode Analisis Data}

Analisis deskriptif, interpretif dan komparatif akan digunakan untuk mengetahui gambaran tentang kriteria-kriteria dan syarat-syarat guna tercapainya atribut Islami dan warisan budaya lokal dari segi fungsi Guna maupun fungsi Citra; yaitu artikulasi desain ornamen masjid.

\section{HASIL PENELITIAN DAN PEMBAHASAN}

Subyek penelitian ini adalah ornamen pada masjid Sunan Ampel di Surabaya, masjid Sunan Giri (masjid Ainul Yaqin) di Gresik, dan masjid Sunan Sendang di Paciran, Lamongan. Sedangkan obyek penelitiannya adalah karakteristik bentuk dan makna ornamen, serta konsepsi desain ornamen masjid Wali yang berbasis budaya dan Islam.

\section{A. Ornamen pada Masjid Sunan Ampel}

Kompleks masjid dan makam Sunan Ampel terletak di kelurahan Ampel, kecamatan Semampir, kota Surabaya. Bangunan di area masjid Sunan Ampel dapat dikelompokkan menjadi: bangunan gerbang Paduraksa, bangunan masjid termasuk menara, dan bangunan makam. Penelitian ini hanya membahas ornamen dari salah satu tipe bangunan tersebut, yaitu gapura paduraksa. Terdapat lima buah gapura paduraksa yang posisinya membentuk sekuen dari area makam kearah luar kompleks masjid dan makam Sunan Ampel sesuai urutan rukun Islam yaitu: gapura panyeksen (syahadat), gapura madep (sholat), gapura ngamal (zakat), gapura poso (puasa), dan gapura munggah (haji).

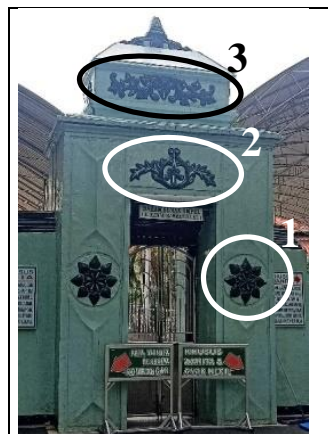

Gapura Panyeksen

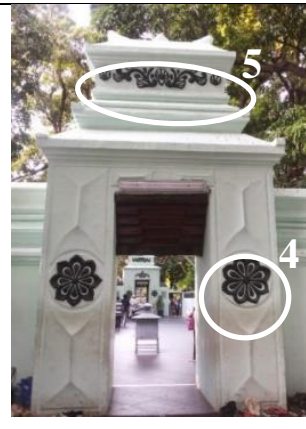

Gapura Madep

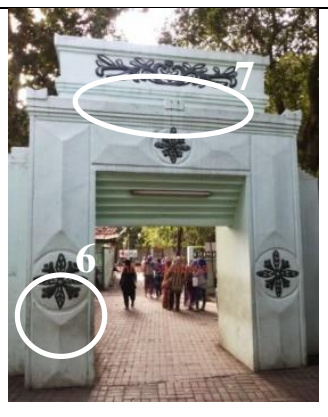

Gapura Ngamal

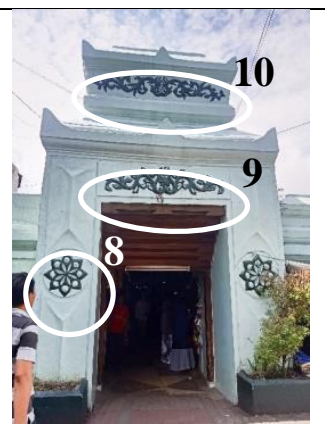

Gapura Poso

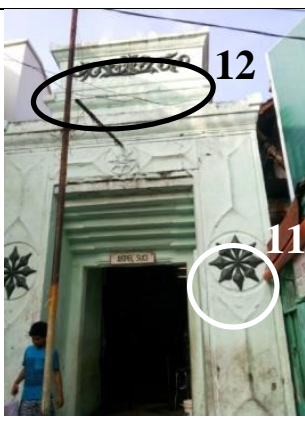

Gapura Munggah

Gambar 1. Posisi Ornamen pada Lima Gapura Paduraksa di Kompleks Masjid Sunan Ampel Sumber : Dokumentasi Penulis (2020) 
Tabel 1. Ornamen pada Gapura Paduraksa di Kompleks Masjid Sunan Ampel

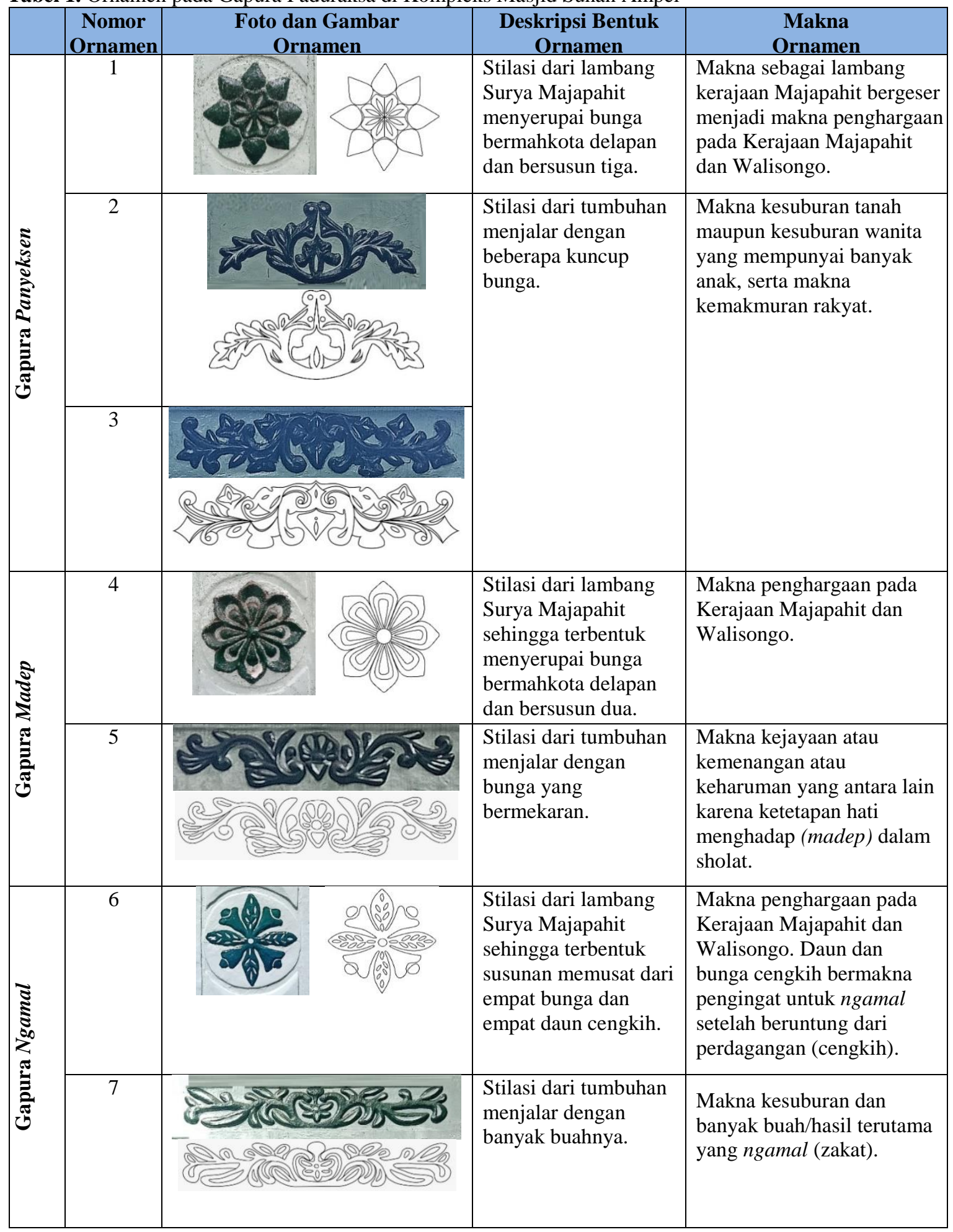




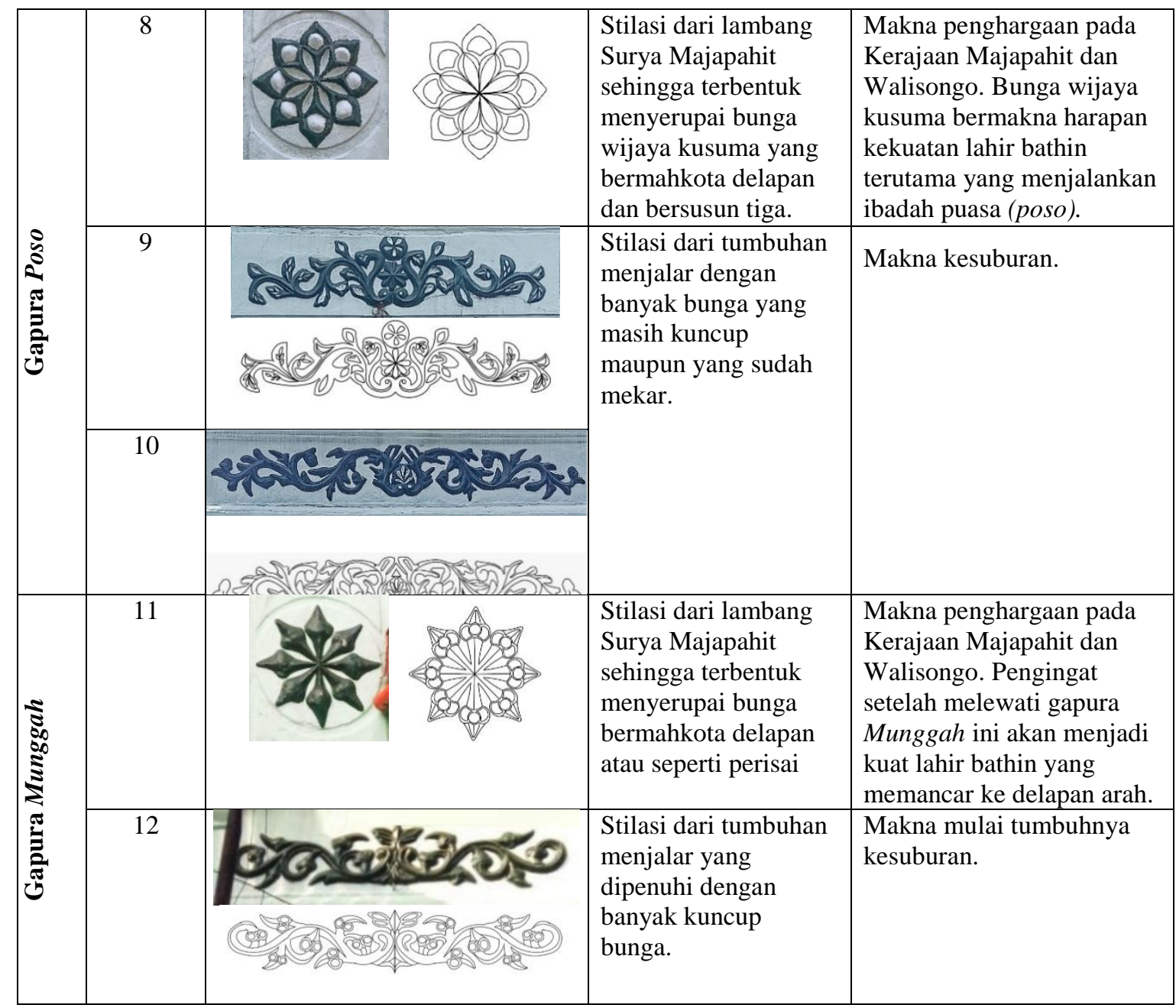

Sumber: Hasil Kajian Lapangan (2020)

Dari ornamen gapura masjid dan makam Sunan Ampel diatas dapat ditemukan bahwa hampir semua ornamen diambil dan diolah dari ragam hias tradisional Jawa serta langgam Majapahit atau pra-Islam yaitu Surya Majapahit dan Lung-lungan atau suluran. Makna ornamen juga mengalami pergeseran dari makna ornamen serupa atau mirip dengan yang ada pada candi Hindu atau Budha akibat pengaruh budaya/tuntunan Islam.

\section{B. Ornamen pada Masjid Sunan Giri}

Masjid Ainul Yaqin adalah masjid yang berada dalam kompleks makam Sunan Giri yang berlokasi di desa Giri, kecamatan Kebomas, kabupaten Gresik, propinsi Jawa Timur. 'Ainul Yaqin' adalah salah satu nama panggilan Sunan Giri. Dalam penelitian ini ornamen masjid Ainul Yaqin dikelompokkan berdasarkan penempatannya menjadi 4 yaitu : ornamen pada pintu paduraksa, ornamen pada kolom soko guru, ornamen pada balok sunduk, serta ornamen pada mimbar. 


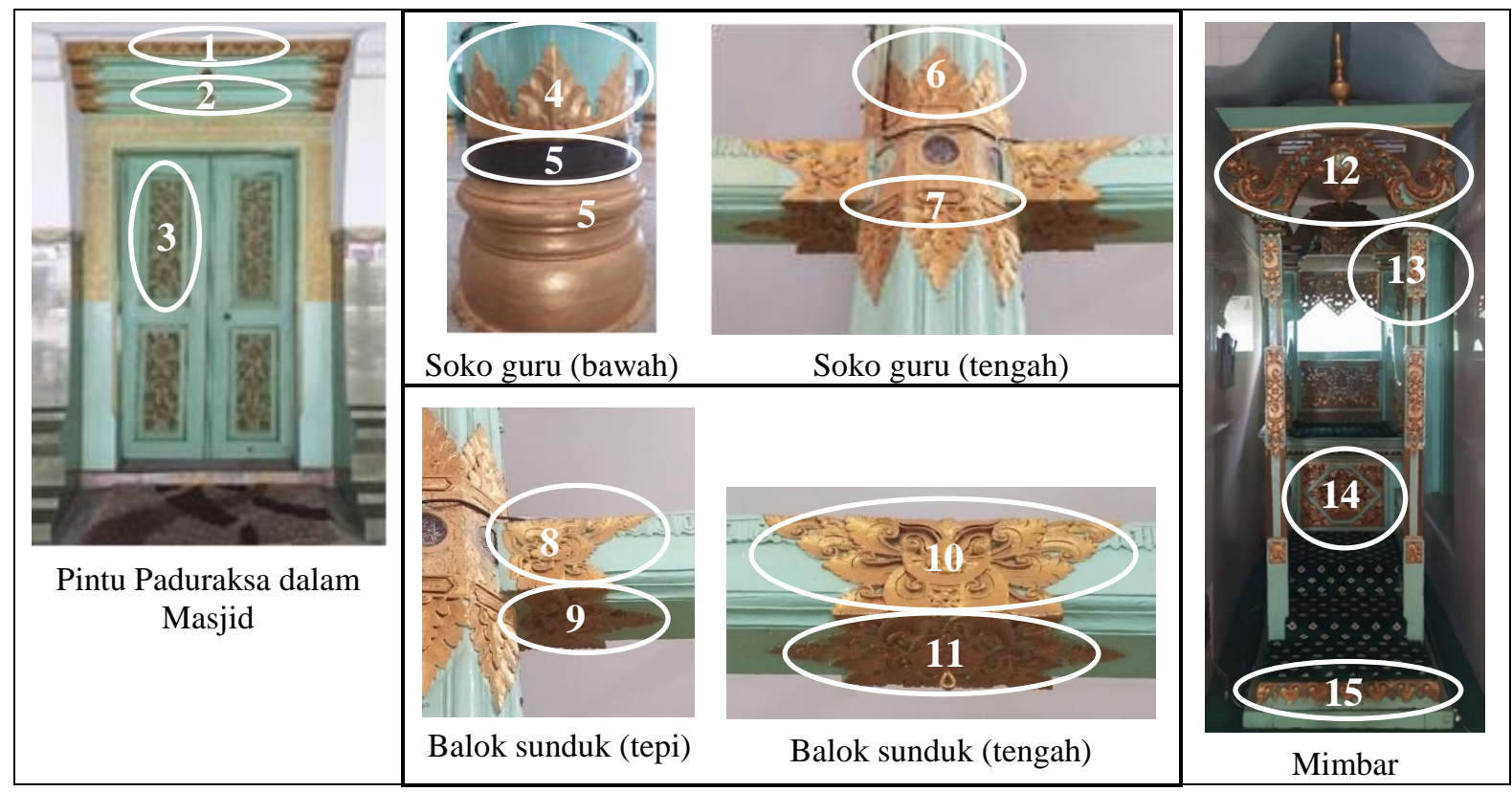

Gambar 2. Posisi ornamen pada Masjid Ainul Yaqin Sumber : Dokumentasi Penulis (2020)

Tabel 2. Ornamen pada Masjid Sunan Giri

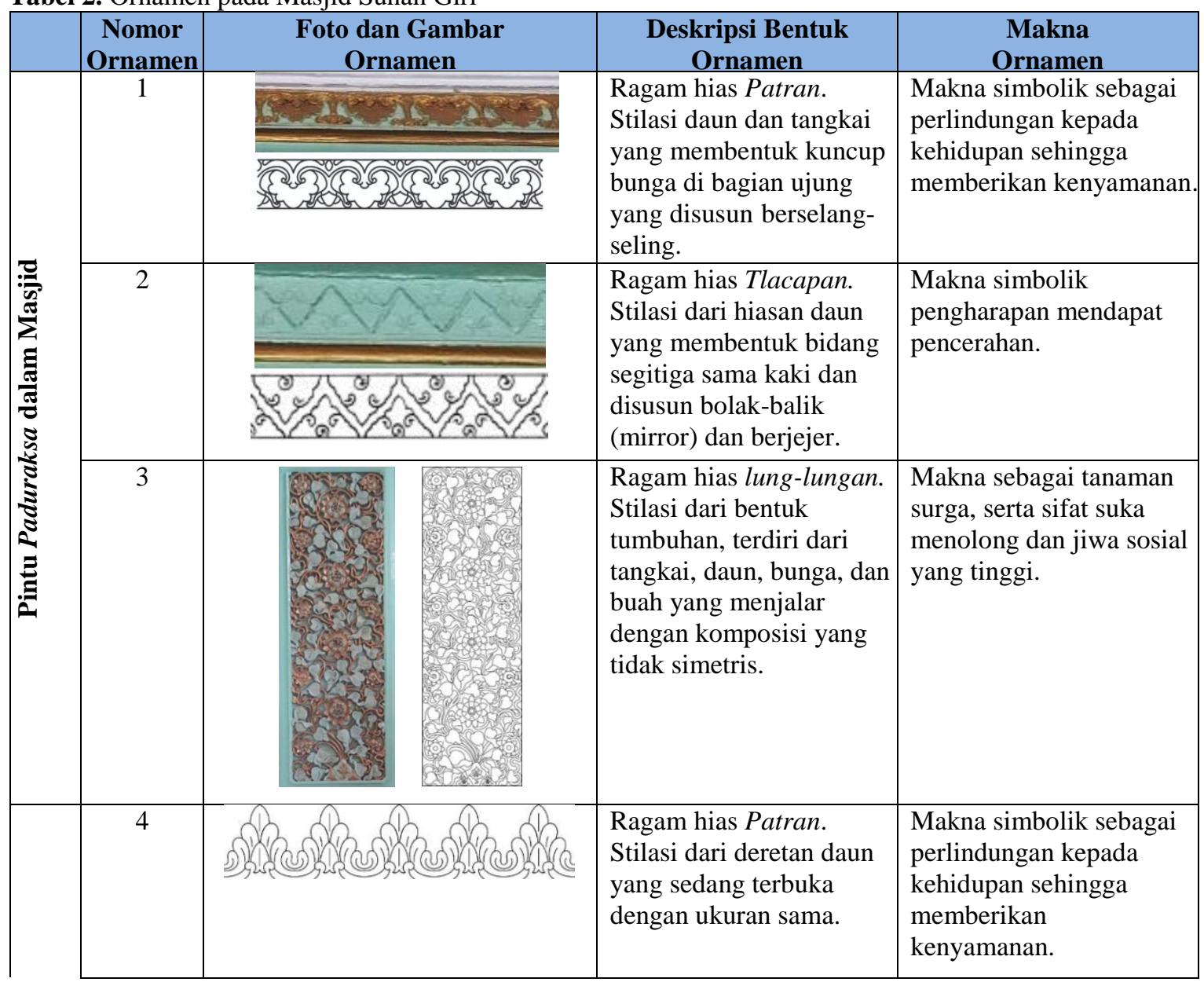




\begin{tabular}{|c|c|c|c|c|}
\hline 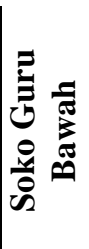 & 5 & (5) & $\begin{array}{l}\text { Ragam hias lung-lungan. } \\
\text { Stilasi dari tumbuhan } \\
\text { menjalar yang terdiri dari } \\
\text { tangkai dan daun saling } \\
\text { tumpang tindih serupa } \\
\text { ragam sulur lengkung. }\end{array}$ & $\begin{array}{l}\text { Makna sebagai tanaman } \\
\text { surga, serta sifat suka } \\
\text { menolong dan jiwa sosial } \\
\text { yang tinggi. }\end{array}$ \\
\hline \multirow{2}{*}{ 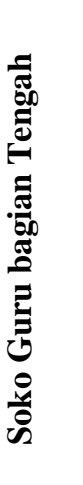 } & 6 & & $\begin{array}{l}\text { Ragam hias Tlacapan. } \\
\text { Stilasi stilasi dari dua } \\
\text { lapisan daun dengan } \\
\text { ukuran berbeda dan } \\
\text { berbentuk dasar segi tiga } \\
\text { sama kaki yang disusun } \\
\text { berderet. }\end{array}$ & $\begin{array}{l}\text { Makna simbolik } \\
\text { pengharapan mendapat } \\
\text { pencerahan atau } \\
\text { keagungan. }\end{array}$ \\
\hline & 7 & 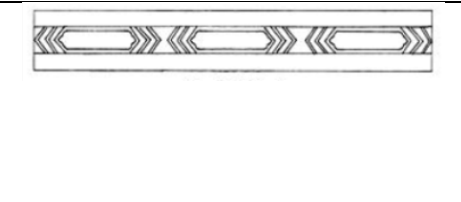 & $\begin{array}{l}\text { Ragam hias Saton. } \\
\text { Stilasi dari kue 'satu' } \\
\text { berbentuk empat persegi } \\
\text { panjang tanpa hiasan } \\
\text { motif daun atau bunga. }\end{array}$ & $\begin{array}{l}\text { Makna simbolik } \\
\text { menyatu (nyawiji) atau } \\
\text { berserah diri kepada } \\
\text { Alloh SWT. }\end{array}$ \\
\hline \multirow{2}{*}{ 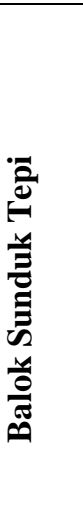 } & 8 & & $\begin{array}{l}\text { Ragam hias Garuda. } \\
\text { Stilasi dari sayap burung } \\
\text { garuda dengan dedaunan } \\
\text { berkomposisi mendekati } \\
\text { simetris yang di ujung } \\
\text { melancip serta di bagian } \\
\text { dasar mirip ekor burung. }\end{array}$ & $\begin{array}{l}\text { Makna pemberantas } \\
\text { kejahatan. }\end{array}$ \\
\hline & 9 & & $\begin{array}{l}\text { Ragam hias Praba. } \\
\text { Berbentuk sulur-suluran } \\
\text { yang meruncing di } \\
\text { bagian ujung serta datar } \\
\text { di bagian pangkalnya. }\end{array}$ & $\begin{array}{l}\text { Makna simbolik cahaya } \\
\text { (nur) atau kebersihan } \\
\text { jiwa manusia. }\end{array}$ \\
\hline \multirow{3}{*}{ 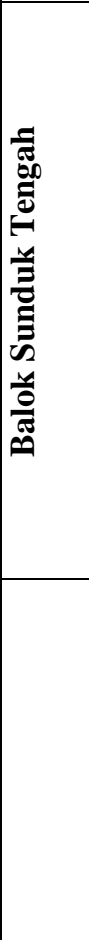 } & 10 & & $\begin{array}{l}\text { Ragam hias Garuda. } \\
\text { Stilasi dari wajah burung } \\
\text { garuda dengan sayap, } \\
\text { serta tangannya yang } \\
\text { bercakar. }\end{array}$ & $\begin{array}{l}\text { Makna simbolik sebagai } \\
\text { kemampuan untuk } \\
\text { memberantas atau } \\
\text { mengalahkan sesuatu } \\
\text { yang bersifat jahat. }\end{array}$ \\
\hline & 11 & & $\begin{array}{l}\text { Ragam hias Praba. } \\
\text { Komposisi dua bentukan } \\
\text { berhadap-hadapan dari } \\
\text { suluran yang meruncing } \\
\text { di ujung dan datar di } \\
\text { pangkalnya, serta surya } \\
\text { Majapahit di tengahnya. }\end{array}$ & $\begin{array}{l}\text { Makna simbolik cahaya } \\
\text { (nur) atau kebersihan } \\
\text { jiwa manusia. }\end{array}$ \\
\hline & 12 & is & $\begin{array}{l}\text { Ragam hias Surya Maja- } \\
\text { pahit diapit dua naga. } \\
\text { Stilasi dari matahari } \\
\text { sedang bersinar, dan ular } \\
\text { naga menghasilkan } \\
\text { komposisi tangkai, daun, } \\
\text { dan bunga membentuk } \\
\text { bidang lengkung dengan } \\
\text { bunga mekar di ujung. }\end{array}$ & $\begin{array}{l}\text { Ragam hias Surya } \\
\text { Majapahit bermakna } \\
\text { penghargaan pada } \\
\text { Kerajaan Majapahit dan } \\
\text { Walisongo, sedangkan } \\
\text { ragam hias Naga } \\
\text { bermakna dunia bawah. }\end{array}$ \\
\hline
\end{tabular}




\begin{tabular}{|l|l|l|l|}
\hline 13 & & $\begin{array}{l}\text { Ragam hias jenis } \\
\text { sorotan'yang diisi } \\
\text { dengan ragam hias jenis } \\
\text { lung lungan. }\end{array}$ & $\begin{array}{l}\text { Makna sifat suka } \\
\text { menolong dan jiwa } \\
\text { sosial yang tinggi. }\end{array}$ \\
\hline 14 & & $\begin{array}{l}\text { Ragam hias jenis } \\
\text { Hiranyagarba. Stilasi } \\
\text { dari tanah, batu cadas, } \\
\text { tumbuhan yang disusun } \\
\text { hingga memenuhi } \\
\text { seluruh bidang seperti } \\
\text { belah ketupat tanpa } \\
\text { bingkai di sisi luarnya. }\end{array}$ & $\begin{array}{l}\text { Makna simbolik sebagai } \\
\text { pengingat sekaligus } \\
\text { ajaran kebajikan kepada } \\
\text { manusia. }\end{array}$ \\
\hline 15 & $\begin{array}{l}\text { Ragam hias Patran. } \\
\text { Stilasi dari daun, tangkai } \\
\text { dan kuncup bunga di } \\
\text { bagian ujung yang } \\
\text { disusun berselang- } \\
\text { seling. }\end{array}$ & $\begin{array}{l}\text { Makna simbolik sebagai } \\
\text { perlindungan kepada } \\
\text { kehidupan sehingga } \\
\text { memberikan kenyamanan. }\end{array}$ \\
\hline
\end{tabular}

Sumber: Hasil Kajian Lapangan (2020)

Dari ornamen masjid Sunan Giri diatas dapat disimpulkan bahwa hampir semua ornamen diambil dan diolah dari ragam hias tradisional Jawa serta langgam Majapahit atau pra-Islam. Ragam hias tersebut meliputi: lung-lungan, patran, tlacapan, saton, garuda, praba, surya Majapahit dan hyranyagarba. Dari ornamen yang ada juga ditemukan bentuk dan makna ornamen akibat terjadinya akulturasi budaya Hindu-Budha (pra-Islam) dengan Islam.

\section{Ornamen pada Masjid Sunan Sendang}

Kompleks masjid dan makam Sunan Sendang terletak di desa Sendang Duwur, kecamatan Paciran, kabupaten Lamongan, propinsi Jawa Timur. Sunan Sendang adalah julukan bagi Raden Nur Rahmat yang dikenal sebagai salah satu tokoh penyiar agama Islam di Jawa selain Sunan Sembilan atau Walisongo. Dalam kompleks ini terdapat tiga macam bangunan utama, yaitu gapura bentar dan paduraksa, masjid, dan makam. Penelitian ini hanya membahas ornamen dari salah satu jenis bangunan tersebut, yaitu ornamen pada gapura paduraksa. Gapura paduraksa yang terdapat dalam kompleks makam ini berjumlah tiga buah.

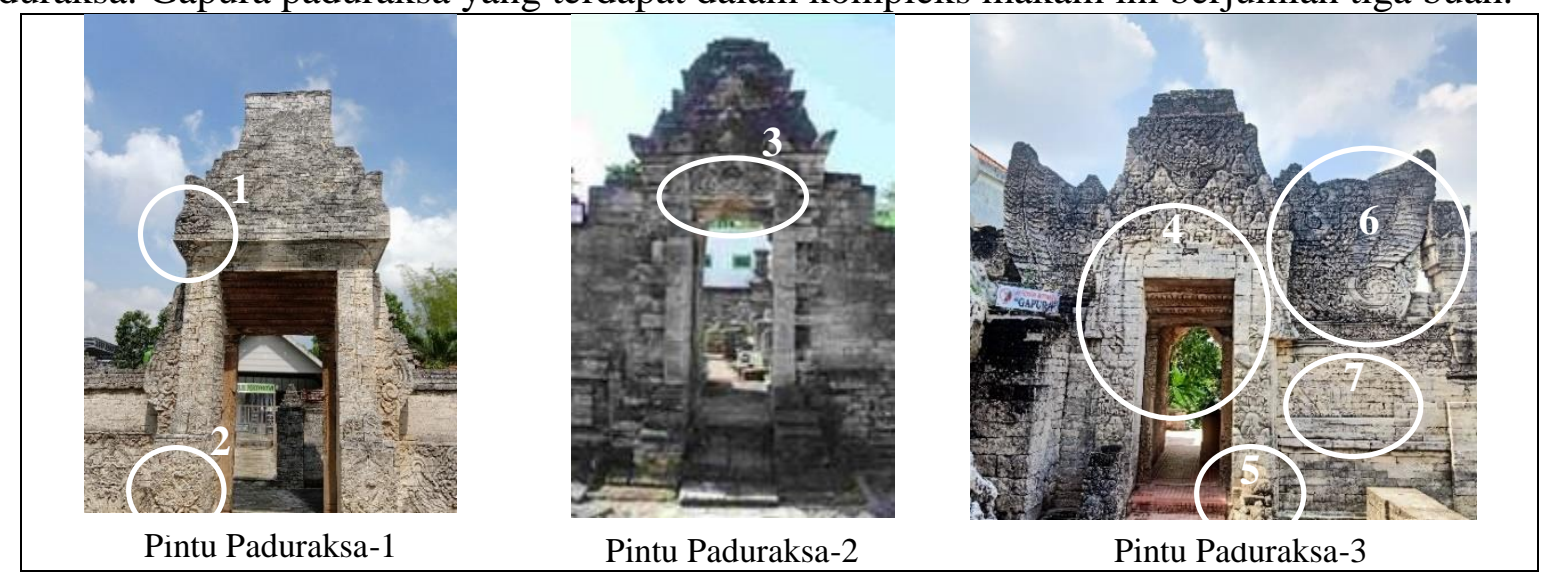

Gambar 3. Posisi Ornamen pada Kompleks Masjid Sunan Sendang

Sumber : Dokumentasi Penulis (2020) 
Tabel 3. Ornamen pada Gapura Paduraksa di Kompleks Masjid Sunan Sendang 1.

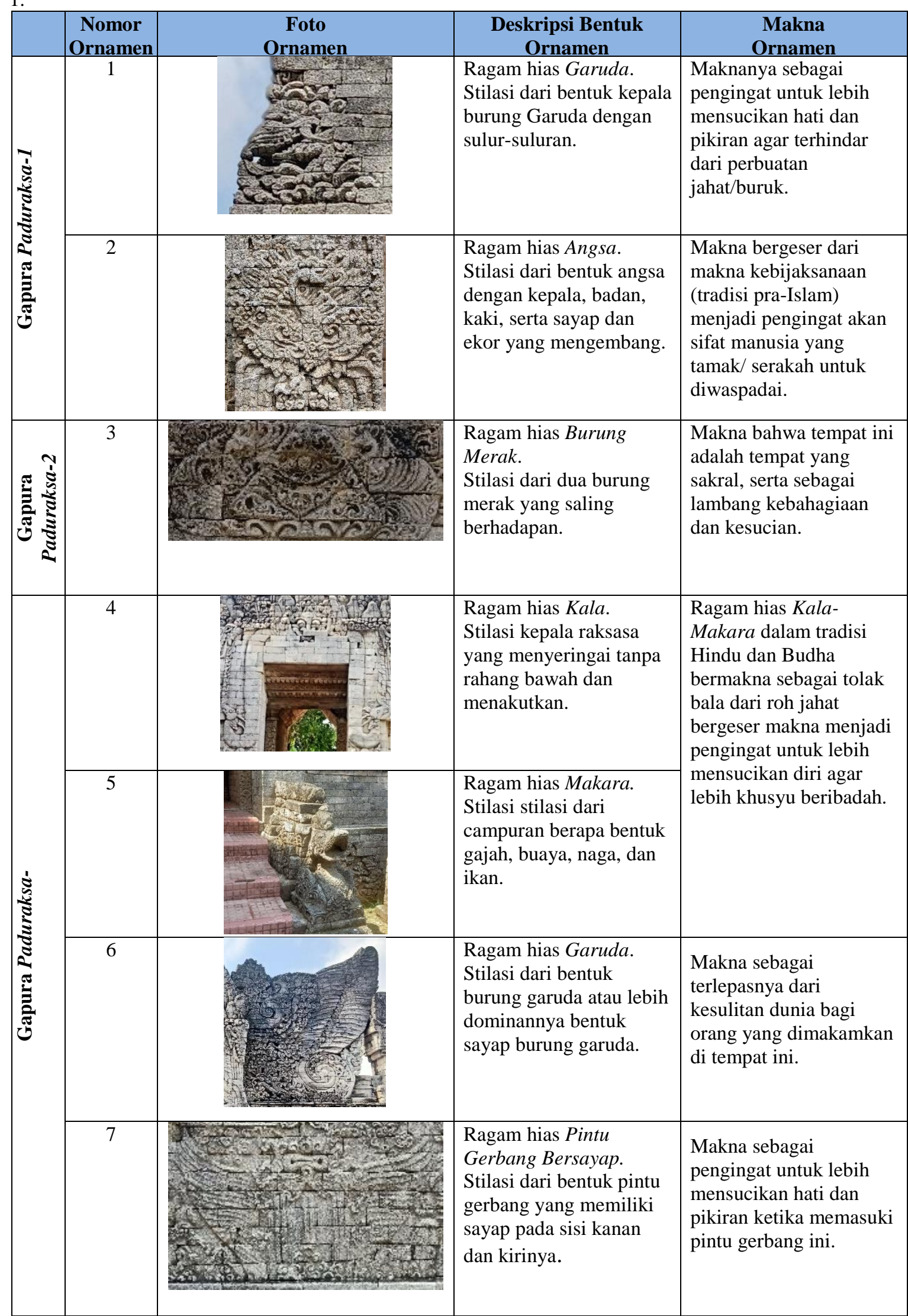

Sumber: Hasil Kajian Lapangan (2020) 


\section{KESIMPULAN}

Dari data dan analis terhadap ornamen pada masjid dan makam Sunan Ampel, Sunan Giri, dan Sunan Sendang tersebut di atas dapat diambil kesimpulan sebagai berikut:

1. Ragam hias yang digunakan pada ornamen dapat dikelompokkan sbb:

a. Geometris, meliputi ragam hias surya majapahit.

b. Flora, meliputi ragam hias lung-lungan, patran, tlacapan, saton, hiranyagarba.

c. Mahluk hidup, meliputi ragam hias kala-makara, garuda, naga, merak, angsa.

d. Alam, meliputi ragam hias praba, rumah.

2. Terjadinya akulturasi pada bentuk ornamen masjid atau makam yaitu dengan melakukan stilasi atau deformasi dari bentuk mahluk bernyawa yang sebelumnya banyak dijumpai pada ornamen candi Hindu atau Budha sehubungan dengan adanya larangan penggambaran mahluk bernyawa dalam ajaran Islam.

3. Terjadinya pergeseran pada makna ornamen masjid atau makam yaitu dengan melakukan penyesuaian dari makna ornamen serupa (yang sebelumnya banyak dijumpai pada ornamen candi Hindu atau Budha) sehubungan adanya tuntunan Islam ketika ibadah di masjid atau makam dalam rangka meningkatkan iman dan taqwa.

4. Bentuk-bentuk ornamen sangat beragam dan khas sehingga menarik untuk dikembangkan bentuknya sesuai dengan fungsi yang dibutuhkan masa kini dengan tetap mempertahankan karakter utama sebagai ragam hias tradisional hasil akulturasi budaya Hindu-Budha dan Islam.

\section{DAFTAR PUSTAKA}

Adiani, Ningroom. (2015). Telaah Ornamen Gapura dan Masjid Ampel sebagai Kekhasan Lokal untuk Meningkatkan Nilai Estetik Souvenir. Seminar Nasional Sains dan Teknologi Terapan III Institut Teknologi Adhi Tama Surabaya.

Budi, Bambang S. (2004). A Study on the History and Development of Javanese Mosque. Journal of Asian Architecture and Building Engineering (JAABE). Vol. 3 No. 1 hal. 189-195.

Iswati. (2016). Kajian Estetik dan Makna Simbolik Ornamen di Kompleks Makam Sunan Desa Sendang Duwur Paciran Lamongan. Arty: Jurnal Seni Rupa. Vol.5 No. 1.

Munandar, Agus Aris. (1999). Berbagai Bentuk Ragam Rias pada Bangunan Hindu-Buda dan Awal Masuknya Islam di Jawa. Jurnal WACANA. Vol. 1 No. 1 hal. 49-69.

Pradana, Rizal Wahyu Bagas. (2019). Ragam Hias pada Masjid Ainul Yaqin Gresik. Seminar Nasional Desain dan Arsitektur (SENADA). Vol. 2 Februari 2019.

Sunaryo, Arya. (2011). Ornamen Nusantara: Kajian Khusus tentang Ornamen Indonesia. Semarang: Dahara Prize.

Supatmo dan Syafii, (2019). Nilai Multikultural Ornamen Tradisional Masjid-Masjid Warisan Para Wali di Pesisir Utara Jawa. Jurnal Imajinasi. Vol. XIII No. 2.

Wahby, Ahmed E.I. (2007). The Architecture of the Early Mosques and Shrines of Java: Influences of the Arab Merchants in the $15^{\text {th }}$ and $16^{\text {th }}$ Century?. Disertasi PhD tidak diterbitkan, Bamberg: Universitat Bamberg.

Wardani, Laksmi K. dkk. (2015). Estetika Ragam Hias Candi Bentar dan Paduraksa di Jawa Timur. Prosiding Konferensi Nasional Pengkajian Seni Art and Beyond Universitas Gadjah Mada. 